Place

Elsevier Editorial System(tm) for Health \&

Manuscript Draft

Manuscript Number: JHAP-D-16-00298R2

Title: Maintaining Physical Exercise as a Matter of Synchronising

Practices: Experiences and Observations from Training in Mixed Martial

Arts

Article Type: SI: Exercise and Environment

Keywords: Mixed martial arts; exercise; health; practice; synchronisation

Corresponding Author: Dr. Stanley Blue, Ph.D.

Corresponding Author's Institution: Lancaster University

First Author: Stanley Blue, Ph.D.

Order of Authors: Stanley Blue, Ph.D.

Manuscript Region of Origin: UK

Abstract: This paper is concerned with the establishment, maintenance, and decline of physical exercise practices. Drawing on experiences and observations taken from a carnal ethnography and rhythmanalysis of the practices involved in training in Mixed Martial Arts (MMA), I argue that maintaining this physical exercise practice is not straightforwardly an outcome of individual commitment, access to facilities, or the availability of free time. It rather depends on the synchronisation of practices: those of MMA, those that support MMA, and those that more broadly make up everyday life. This research suggests that increasing rates of physical activity might be better fostered through facilitating the integration of combinations of healthy activities into everyday life. 
Dear Dr Pearce,

Thank you for your email. The reviewers' comments have once again strengthened the paper and I hope that you find my responses to these final requirements to be acceptable. My responses and edits are outlined below:

1. I have changed the title so that the idea of synchronisation and the focus on the temporal is highlighted as key topics. It is now: Maintaining Physical Exercise as a Matter of Synchronising Practices: Experiences and Observations from Training in Mixed Martial Arts

2. In response to reviewer 3's suggestion to add nuance on pages 3-4 to an overstatement about the social determinants of health, I have rewritten the last two paragraphs of this section.

3. In response to reviewer 1 's comment on page 1 line 57 about the point on methodological individualism - I have edited in line with the reviewer's suggestion to say these approaches focus either on the individual or the infrastructure (and thereby miss how everyday life is organised).

4. In response to reviewer 1's comment that it is unclear how providing access to facilities separates out the individual from context, I have edited this point so that it is in keeping with the rest of the article that focusing on either the context or that the individual fails to capture the significance of the organisation of everyday life.

5. In response to reviewer 1 's comment I have removed the claim about 'temporal interventions' on page 19 line 36 and strengthened the final point in line with their suggestions.

6. In response to reviewer 1 's comment I have deleted that reference to running clubs on page 19 and tried to strengthen the central claim about scheduling exercise with wider society.

7. In response to reviewer 1 's suggestion I have added three sentences on page 8 to make more of the idea that doing things with exercisers first is a useful method for staging more effective talk afterwards.

8. In response to reviewer 1's suggestion to connect with Katrina Brown's paper on the methods, and reviewer 2's suggestion to cite more articles from this journal, I have added further references on page 8 .

9. Reviewer 2 asked that I check the terminology changes between public health and health promotion on page 2 . I have done this and edited for consistency.

10. In response to reviewer 2's comments I have checked and edited the references to the Department of Health, and taken the opportunity to re-check and update all references and links.

11. In response to reviewer 1's comment about the turn of phrase on page 7 line 31 about this methodology being 'well taken up' - I have deleted this part of the sentence because the point that this approach has broader significance for sociological enquiry is made above.

12. I have rewritten the last sentence for clarity in response to reviewer 2's comment. 
13. In response to reviewer 1's comment, I have checked and edited the reference list for accuracy and consistency.

14. In response to reviewer 2 and 3's comments I have carefully proofed the manuscript.

I hope that you find these revisions acceptable and that you will consider this article for publication.

Kind regards,

Stanley Blue 


\title{
Maintaining Physical Exercise as a Matter of Synchronising Practices: Experiences and Observations from Training in Mixed Martial Arts
}

\begin{abstract}
This paper is concerned with the establishment, maintenance, and decline of physical exercise practices. Drawing on experiences and observations taken from a carnal ethnography and rhythmanalysis of the practices involved in training in Mixed Martial Arts (MMA), I argue that maintaining this physical exercise practice is not straightforwardly an outcome of individual commitment, access to facilities, or the availability of free time. It rather depends on the synchronisation of practices: those of MMA, those that support MMA, and those that more broadly make up everyday life. This research suggests that increasing rates of physical activity might be better fostered through facilitating the integration of combinations of healthy activities into everyday life.
\end{abstract}

\section{Keywords}

Mixed martial arts; exercise; health; practice; synchronisation; everyday life

\section{Introduction}

Physical exercise is promoted in the UK as an essential part of maintaining good health (see for example Department of Health, 2011b; NHS Choices, 2015; NICE Pathways, 2016) and as an effective measure to tackle non-communicable disease (see for example Lee et al., 2012). Despite this kind of health promotion and attempts at intervention, rates of physical activity remain low. In England, for example, only $66 \%$ of men and $56 \%$ of women claim to meet the Chief Medical Officers' recommendations for physical activity (Department of Health, 2011a) and these self-reported figures are considered to be radically over-estimated (Prince et al., 2008). The effectiveness of health promotion interventions has, so far, been limited. This is in part because the problem tends to be addressed as one of enabling and constraining the healthy or otherwise behaviour of individuals. On the one hand, government-led health initiatives seek to provide more information to people to encourage them to do more physical exercise. On the other, public health guidelines advise investment in the design of the built environment and new facilities to increase access to, and 
availability of, places in which to exercise. By focusing on either the choices of individuals or the constitution of the built environment, such approaches envision that healthy behaviours would be adopted should citizens have access to sufficient information and opportunity. Both methods fail to capture more detailed accounts of how physical exercise practices are made, maintained, and broken, and of how the organisation of everyday life shapes rates of physical activity.

Drawing on a carnal ethnography and rhythmanalysis of participating in the physical exercise practice and combat sport of Mixed Martial Arts (MMA), I extend conceptual resources from theories of practice and rhythmanalysis to argue that the maintenance of physical exercise practices does not depend straightforwardly on individual motivation or commitment, on access to facilities or places in which to exercise, or on the availability of 'free' time in which to perform exercise. Instead, the forging of such places, times, and commitments, should be recast as the outcome of the reproduction of a given physical exercise practice, such as MMA. I argue here that the maintenance of physical exercise practices depends on the synchronisation of supporting practices (in this case dieting and strength and conditioning) and with broader practices that make up everyday life.

I begin with a brief discussion of selected, contemporary public health approaches designed to encourage levels of exercise and curb sedentarism so that I can, secondly, outline an emerging and significantly alternative approach to public health based on practices and rhythms that I argue could be developed to advance strategies designed to increase rates of physical activity. Thirdly, I give a methodological account of the study, which builds on previous research on combat sports and that aims to capture the embodied experience of maintaining this physical exercise practice, extending it through a rhythmanalysis to consider the temporal dynamics of everyday life involved. I conclude that those who would seek to intervene in and shape physical exercise practices should pay attention to the integration of physical exercise practices, and supporting practices, within broader patterns of activity that make up everyday life.

\section{Contemporary Public Health Approaches to Physical Activity}


Rates of non-communicable disease are rising fast (Beaglehole et al., 2011). Although new evidence shows that when it comes to obesity and weight loss 'you cannot outrun a bad diet', research suggests that "[r]egular physical activity reduces the risk of developing cardiovascular disease, type 2 diabetes, dementia and some cancers by at least $30 \% . "$ (Malhotra et al., 2015, p, 1). The implication is that rising levels of obesity are better attributed to significant changes in the production and consumption of food, while sedentarism is a core contributor to growth in non-communicable disease more generally. Getting people moving more, quite rightly, remains at the forefront of UK health promotion strategies.

While health promotion strategies and interventions fall under a broad spectrum; two distinct approaches can be discerned. The first approach explains health as a result of individual choice that can be influenced by providing information and incentives to shape attitudes and values. One current example of this approach in the UK is the Change for Life Campaign. ${ }^{1}$ This government-led initiative provides information, advice, and 'lifestyle tips' to help people make healthy choices such as moving more, eating well, and drinking less alcohol. Its ambition is to influence and motivate individuals to adopt and commit to a healthy lifestyle. Such approaches have been well critiqued within the literature on public health for ignoring the social circumstances that shape who is able to adopt and choose particular lifestyles, and for misrepresenting health inequalities as the outcome of individual choice (e.g. Frohlich et al., 2001; Thompson and Kumar, 2011).

In response to such critiques, health promotion has sought to address better what it calls the 'social determinants' of health and health inequalities (e.g. Baum, 2008; Marmot et al., 2010). Part of the approach has been to influence and affect the 'social context' of health behaviours by increasing access to, and the availability of, various health resources, including, for example, public places in which to exercise. An example of this kind of health promotion and type of intervention can be seen in the NICE (National Institute for Health and Care Excellence) 2008 guidelines on physical activity and the environment. ${ }^{2}$ These guidelines endorse investment in the built environment and the provision of facilities, amongst other recommendations, as a way of encouraging increased rates of physical

\footnotetext{
1 See http://www.nhs.uk/change4life/Pages/change-for-life.aspx

2 See https://www.nice.org.uk/guidance/PH8/chapter/1-Recommendations
} 
activity. Approaches that seek to capture the 'social determinants' reveal significant variations in population health that correlate with, for example, place. However, contemporary approaches to public health could do more to examine how the dynamics of everyday life shape the use of facilities and the built environment, that is, to understand how exercise practices are made and maintained in a given place.

In recasting understandings of physical activity as more straightforwardly the result of individual commitments, access to facilities, and the availability of free time, public health could develop new approaches to investigate, for example, the ways in which exercise practices are combined with potentially supporting practices such as eating and possibly conflicting practices such as family and social life; it could develop new accounts of how healthy and unhealthy practices emerge in social life; and it could take further steps to understand how such practices and combinations might be fostered and disrupted.

\section{Practices and Rhythms}

One way of achieving this is to turn to an exploration of the rhythms involved in maintaining a physical exercise practice to reveal new opportunities for shaping rates of physical activity. In social theory, authors such as Bourdieu (1977) and Giddens (1984) have developed practical accounts of social action which complicate questions about the limits of individual agency and the determinacy of social structure. From such accounts, what has been called a 'practice turn' in social thought (Schatzki, Knorr-Cetina, and Savigny, 2001) has challenged analyses which have separated out agency from structure and which have separated micro and macro levels of social action. Instead, authors following this approach advocate taking practices, social phenomena in their own right, as the central unit of conceptualisation and enquiry. This unit of a practice is sometimes described as a routinised activity which includes various forms of mental and bodily actions, sayings and doings, knowledges and objects. Reckwitz summarises:

"A practice is thus a routinized way in which bodies are moved, objects are handled, subjects are treated, things are described and the world is understood." (Reckwitz 2002, p, 250) 
Rather than belonging to an individual, practices are shared and repeated by people. Indeed in this formulation people become the 'carriers' of practices as entities (see Shove and Pantzar, 2007) which, significantly, have their own histories, geographies, and trajectories. Examples of practices are showering (Hand, Shove, and Southerton, 2005), eating (Warde, 2013), and driving (Shove, Watson, and Spurling, 2015). Accounts of social action that have adopted such an approach have reframed understandings of changing patterns of consumption (Warde, 2005), and particularly those that significantly impact on environmental sustainability (see Shove and Spurling, 2013).

Recently this approach has been taken up with public health concerns in mind. For example, Cohn (2014) has argued for a reconceptualisation of health behaviours in terms of health practices to capture the emergent and contingent properties of people's activities. In the same special issue, Nettleton and Green (2014) have developed a social practice account of how mobility practices change. Maller (2015) has drawn attention to the opportunities a practice approach presents for understanding health regarding both its empirical application and its emphasis on the critical role of materiality. Hitchings and Latham (2016) have investigated how exercise practices become attached to certain environments, for example, how running has become an activity that takes place indoors. And Blue et al. (2016) have described the history and trajectory of smoking as a practice to illustrate potential new possibilities for public health intervention in the development of (un)healthy practices.

What each of these approaches has in common is that they argue for reframing the conceptual and analytical focus of public health away from questions about what enables and constrains more and less healthy behaviours, in favour of an examination of the dynamics of practices (Shove et al., 2012). They seek to explain how changes in population health are an outcome of changes in the order and organisation of everyday life. More than an analytical category, everyday life is the methodological site which permits an investigation of how practices emerge, persist, and decline, connect in sequence and combination, and affect and shape each other.

The concept of rhythms as developed by Lefebvre ([1992] 2004), I argue, is a useful bedfellow for practical accounts of social action that seek to understand the establishment, maintenance and decline of practices. Both approaches emphasise and deal with the 
reproduction of activities that constitutes the everyday and how it changes. While the concept of practice allows us to identify a given phenomenon or activity and trace its histories and geographies over time and across different places, an analysis of rhythms provides us with further conceptual leverage for understanding the effect that the reproduction of a given practice has on other practices.

Rhythmanalysis has been explored, for example, in relation to nature, place, mobilities, and bodies in a collection edited by Edensor on Geographies of Rhythm (2010) and in relation to the city in an edition on Urban Rhythms by Smith and Hetherington (2013). As of yet, these ideas have not been developed within the field of public health. Health initiatives designed to increase the uptake of physical activity have, to some extent, attended to issues of timing, so-called 'time poverty', and the organisation of daily life. For example, sports centres schedule exercise classes to fit around standard 'office hours', and offer flexible gym memberships. However, what such initiatives are unable to account for is how the temporal organisation of the day is made, and how practices become more and less malleable, more and less able to be 'slotted in' around other activities. This paper brings theories of practice together with rhythmanalysis to provide a new conceptual frame for understanding the changing stability of a given physical exercise practice as an outcome of its synchronisation with supporting and broader practices in everyday life. In the following section, I detail how this conceptual frame can be applied through detailed ethnographic work.

\section{Training in Mixed Martial Arts}

I illustrate my argument that maintaining a physical exercise depends on effective synchronisation with the practices of everyday life with experiences and observations taken from a three-year auto-ethnographic study of the practice of Mixed Martial Arts (MMA). MMA is a combat sport growing in popularity in the UK. 'Mixing' techniques and practices from a range of combat sports and traditional fighting styles, MMA has become a discipline and system in and of itself. Participants learn techniques in striking (usually taken from Boxing, Kickboxing, Muay Thai and Karate), in controlling an opponent (from Wrestling, Judo and Grappling) and in submission (from Brazilian Jujitsu and Catch Wrestling). Mixed Martial Artists incorporate these techniques in various ways to complement and suit their individual strategies, martial and physical backgrounds, and body shapes to develop their own mixed 
style of fighting. While the teleology of this practice is to prepare for competition against an opponent, to use punches, kicks, elbows and knees, chokes and locks to win a fight, in actuality very few participants ever compete in this sport and when they do it is more often at an amateur rather than professional level. The demands of preparation, both in terms of skill and physical fitness, as well as its growing popularity and the effective mainstreaming of the sport, mean that for a vast majority of participants, this exercise practice is about regular training in and for itself, rather than for competition.

There have been a number of anthropological and sociological studies of combat sports and martial arts. Selected examples include Wacquant's classic study of Boxing (2004); Downey's exploration of Capoeira ${ }^{3}$ (2005); and more recently Spencer's work on MMA (2012). Following Wacquant's "apprenticeship-based study of boxing as bodily craft" $(2014,1)$, these 'fighting scholars' (Sanchez and Spencer, 2013) have made the case for, studied, and drawn out the embodied experience of initiation, learning, and participation in the process of becoming a Boxer, Capoeirista ${ }^{4}$, or Mixed Martial Artist. Here, however, I am not concerned with the development of identity, or the process of embodied learning. Instead, the focus of this paper is an examination of the maintenance of a physical exercise practice in relation to the broader set of practices that make up everyday life.

Wacquant's pioneering work develops an 'enactive ethnography' stressing that "... it is imperative that the sociologist... to the greatest extent possible ... [puts] his own organism, sensibility, and incarnate intelligence at the epicentre of the array of material and symbolic forces that he intends to dissect..." (Wacquant 2004, p, viii). This 'carnal sociology', a type of immersive fieldwork based on performing the phenomena under study, is advocated not only for the study of physical activity like Boxing, or Mixed Martial Arts but sociological enquiry more generally. I follow Wacquant in this position. Until one has experienced the bodily rhythms and intensities of an eight-week training camp in preparing for a competitive fight it is impossible to know the ordering effect that meal times and training times have on one's daily schedule; it is impossible to understand the impact of weight management on one's relationships with friends and significant others; and it is impossible to fully appreciate how training comes to be a priority over and above all else.

\footnotetext{
Capoeira is a Brazilian martial art that utilises techniques that resemble dancing and acrobatics to deliver effective kicks. 4 A Capoeirista is someone who 'plays' Capoeira, as a Judoka is someone who plays Judo.
} 
While the adoption of this 'carnal ethnography' (Wacquant, 2015) was essential for getting at the embodied and unsaid aspects of the maintenance of this exercise practice, interviews were also central to the research strategy. Sayings, after all, are a part of any doings, and as Hitchings has argued, 'people can talk about their practices' (2012). As such, I make use of interviews and conversations with fellow practitioners to get at and understand idle conversation in the gym (see Crossley 2006) as a way of interpreting and explaining how Mixed Martial Artists maintain their physical exercise practices beyond what it felt like for me to experience the demands of this practice myself. Thus, as they are in Wacquant's study, interviews were conducted, both formally (recorded and transcribed) and informally (as part of conversations in and around the gym and noted down at a later stage). Among the uncountable conversations that I had with my training partners and an extensive amount of 'time' spent on the mat, ten formal interviews were conducted. I emphasise that to better decode participants' 'sayings', to interpret their meanings, and to be able to contextualise the cues and signs of this practice, it is entirely necessary to have had one's body disciplined through the training of MMA. However, it was only through participating in this practice, through having my body and my practices conditioned by the routines of the Mixed Martial Artist, that I recognised that it was necessary to understand more about how life outside the gym shaped the maintenance of this practice. Both Brown (2016) and Ward (2016), also in this issue, have highlighted the significance of performing the practice under study with participants as a way of staging more in-depth interviews with them afterwards.

The carnal ethnography developed by Wacquant and adopted and adapted by others does not provide a full array of tools to be able to study the maintenance of this physical exercise practice within and in relation to other practices in everyday life. This is because they focus on a single practice, the martial art or combat sport under question itself. It would have been impossible to understand how participants maintained their MMA practice without knowing more about how that practice was related to and connected with supporting activities, as well as how that bundle of activity was integrated with activities in their lives outside the gym. To get at these relationships between combinations of practices that make up and sustain MMA routines and broader practices in everyday life, I extend Wacquant's carnal ethnography through Lefebvre's 'previsionary image of the rhythmanalyst'. He writes: 
"The rhythmanalyst will not be obliged to jump from the inside to the outside of observed bodies; he should come to listen to them as a whole and unify them by taking his own rhythms as a reference by integrating the outside with the inside and vice versa." (Lefebvre [1992] 2004, p, 20)

Building one step on from a carnal ethnography I argue that what is required is not an immersion in the field to get closer to the research object, but instead recognising the process of immersion and routinisation itself as the central story. ${ }^{5}$ Taking on the methodological position of the rhtyhmanalyst required more than just participating in the training, it required more than further participation in supporting activities, and it required more than becoming so immersed in this practice as to compete in this potentially dangerous sport. It required instead, as Lefebvre describes, starting with my own rhythms, using those to interpret and understand interviews with fellow participants, and recognising my position as neither inside or outside, observant or participant, or participant-observer, but as fighting scholar (Sanchez and Spencer 2013) and rhythmanalyst (Lefebvre [1992] 2004).

Such a methodological approach demonstrates as I illustrate below, that a closer inspection of rhythms and practices provides a new window onto the temporal organisation of everyday life and how routine practices with significant health implications such as physical activity emerge and change.

\section{From Temporal Requirements to the Synchronisation of Practices}

The first insight from this project is that physical exercise routines are not maintained in isolation, but in combination with other practices. In the first instance, MMA draws on and 'mixes' techniques from a variety of disciplines and styles of martial art - it is itself made up of different practices. The Mixed Martial Artists that I trained with considered it essential to practice all three aspects of the discipline:

"If you want to be a well-rounded fighter you've got to spend your time working on stand-up, wrestling, and groundwork. Some people just come to Kickboxing, but you

\footnotetext{
5 Whilst it would be possible to recount a story of how I personally first became involved Mixed Martial Arts, such a narrative would only reproduce an understanding of individual motive and circumstance that I am attempting to critique and that is unable to account for the process of synchronisation of practices that I go on to describe.
} 
know they are never going to make it to the advanced [MMA] class because they can't wrestle or grapple." (Bobby)

Most gym members would practice at least three times per week so that they could get enough 'mat time' to develop skills in each of these sets of techniques. Beyond the mat and the gym, there was a consensus that various activities outside of attending the classes were also crucial to one's development as a martial artist and a fighter. Darryl explained:

"For me, I have realised it's really important that I eat right... otherwise I just don't have the energy [for training]. Also it kind of keeps me focussed. If I'm eating right I'm on the wagon and focussed on training." (Darryl)

Certain ways of eating, whether eating healthily, at more regular and specific times of the day, or eating a specific amount of macronutrients were considered by many participants to be a biological necessity (food as fuel for training) and part of a regimen that kept fighters on a disciplined path of bodily preparation and development. Practices of weightlifting, running, stretching, relaxing, and especially strength and conditioning were also understood to be an essential part of a 'good' MMA routine:

"I make sure I get to the gym [for strength and conditioning] three times [a week]. Because you won't get fitter or stronger by just doing the classes. There isn't enough time in the classes for that kind of stuff... If you go to the classes and don't do anything else when it comes to sparring, you'll get outworked..." (Tommy)

On first reflection, it might appear that the maintenance of MMA as a physical exercise practice requires practitioners to be able to meet the temporal demands of both the practice of MMA and additional practices such as dieting and strength and conditioning. Such an analysis has been well developed within theories of practice. Southerton's work on the temporal organisation daily life suggests that:

“... practices come with sets of requirements necessary for competent and meaningful engagement... Engaging in one practice can rule out engagement in another or require the performance of a connected practice." (Southerton 2006, p, 440). 
Southerton describes that practices which have a fixed location in daily schedules, for example an evening MMA class, anchor the temporal location and distribution of other more malleable practices which are 'slotted in' around practices with more fixed temporal requirements, like eating, strength and conditioning, watching television, sleeping, working and commuting.

Southerton's argument shows up the interdependencies of practices in organising the everyday lives of Mixed Martial Artists. However, whilst nearly all Mixed Martial Artists engaged in additional practices of strength and conditioning and dieting, they did so in different ways that mattered for the objective temporal features of practices, that is, in terms of their periodicity, duration, and coordination with others, and therefore for their fixity and malleability within the temporal organisation of the day. Some participants worked out three times a week on their own, while others worked out every day with their training partners. Freddy described the different ways that eating figured into the daily routines of members of the gym:

"People do it differently. Some people just eat clean, but others eat like six meals a day. It doesn't really matter it's just what works for you."

- Does everyone have to have a special diet to be able to do MMA?

"Well, you [won't] last very long eating [fast food]!" (Freddy)

In this excerpt, Freddy is explaining that the idea that you would eat 'normally', that is, without monitoring how what you were eating affected your performance, was ridiculous to those training in Mixed Martial Arts. However, it also shows that there are legitimately different ways for Mixed Martial Artists to achieve this.

Extending Southerton's notion that routine is the outcome of the temporal organisation of daily life with ideas from Lefebvre's rhythmanalysis can help us to understand how such practices connect and come to support each other despite having varying objective temporal features. Instead of positing that practices come with more or less fixed temporal requirements (eating six meals a day, training three times a week), we might consider that it is the repetition of those practices, their rhythms that enable them to support, collaborate, 
and mutually reinforce each other. It is their repetition in combination that shapes their malleability and flexibility within the temporal rhythms of the day. Lefebvre describes this process, the establishment of everyday, 'healthy' routine as eurhythmia':

"Eurhythmia? Rhythms unite with one another in the state of health, in normal (which is to say normed!) everydayness..." (Lefebvre [1992] 2004, 16)

The emergence, establishment, and maintenance of a physical exercise practice, like MMA, do not depend straightforwardly on its malleability to be slotted into the already configured temporal organisation of the day. The ability to fit in is not dependent on the objective temporal features of that practice. In fact, both the temporal features of a practice and the temporal organisation of the day are subject to change. Fitting in is, therefore, a contested and ongoing process which rather depends on the harmonious integration and synchronisation of combinations of practices. In this case, the practice of MMA is maintained because it is reproduced in relation to (heterogeneous) patterns of dieting and strength and conditioning.

Maintaining a physical exercise is not just about 'finding the time' to do the practice itself. Moreover, it is not just about finding the time to do accompanying practices. There is more to the idea of synchronisation than effectively co-ordinating multiple times. Synchronisation is about the process of developing and maintaining eurhythmia. The more that combinations of activities are repeated, the more they shape the times and spaces of other practices. Synchronisation is about how practices become what Southerton describes as temporal anchors, or as I go on to explain, how certain practices come to dominate others.

\section{Dominating Practices}

For practitioners to maintain the practice of Mixed Martial Arts, this combination of activities has to become synchronised with the broader range of practices that make up everyday life. Once synchronised and harmoniously integrated with each other, practices of MMA, dieting and strength and conditioning effectively strengthen their ties, becoming

\footnotetext{
6 Lefebvre does not use the term eurhythmia to refer to the health of an individual person, but rather to describe an order of rhythms as healthy, synchronised and in harmony. It is a point of debate as to whether practicing MMA is good for one's long term health. The notion of eurhythmia describes a harmonious relationship between rhythms (and here, practices). Practices which are arguably unhealthy such as drinking alcohol and smoking tobacco may also be described as eurhythmic when they are considered to be mutually supporting and reinforcing.
} 
reproduced more regularly together, to the point that they are more resilient to disruption and come to dominate and reconfigure other practices. I illustrate this process here by drawing on an example from my own experience, though my training partners also spoke about this reconfiguration of their routines.

After two years of practising MMA and becoming more and more involved in training, I began to prepare for my first competitive fight. While I had already noticed that eating and training had become fixed practices (or as Southerton describes them 'temporal anchors') in my daily routine, as training intensified in preparation for the competition, I noticed a significant change in other daily practices as well. Socialising with friends outside of the gym, going out and having a drink were all off the cards, partly for abstinence reasons (hangovers and getting punched in the head don't really mix!), but partly because resting, recovering and even getting in another training session seemed to take priority. Working and studying, became practices that were 'slotted in' around the expanding temporal demands of training.

Lefebvre's work on the everyday and especially his work on rhythmanalysis can help us to understand this shifting and reconfiguring of the temporal organisation of practices in everyday life. He writes:

"The relationship between forces, which requires the domination of one force and draws on the relations of alliance as means (and not ends), is accompanied by a disassembly of times and spaces." (Lefebvre [1992] 2004, p, 68)

'Forces' here refers to the repetition of practice, or rhythms, that affects the temporal and spatial organisation of everyday practices. The alliance or collaboration of supporting practices that constitutes the maintenance of MMA practice affects, shapes, and disassembles the times and spaces of everyday life. In effect, through repetition, the supporting practices of MMA become a dominant set of practices that in turn disrupt others.

The common experience of becoming more and more involved in Mixed Martial Arts was often spoken about as being described from 'the outside' as unhealthy, obsessive, or addiction. Ali described it like this: 
“People always say I'm obsessed with training, like if I can't go out or something like

Without having experienced being drawn into this physical exercise practice, one might interpret Ali's words as accounting for and explaining her motivations or personality that inform her commitment and 'sacrifices' towards the goal of developing her martial skills. However, this is only in part her intention. Her refusal of the term 'obsessed' undermines such an interpretation. Indeed the meaning behind the statement is better interpreted as those that are 'on the outside' do not understand 'what it takes' and 'what it means' to be involved in this practice. She is claiming that her inability to attend a social event is not a matter of obsession, addiction, or individual commitment. Sacrifice here should be heard as a refusal of the activities that one does not do if following such a routine. Ali is gesturing towards the idea that maintaining this practice, which in part is about successful development and progression, requires a reconfiguration of the times and spaces of everyday life. It is not that she is 'addicted' to training Mixed Martial Arts, but that these socially organised times and spaces are not compatible with the times and spaces of socialising on a night out.

What this example shows is that when practices are regularly reproduced in combination and synchronisation, as eurhythmia, they come to dominate or conquer other rhythms, that is the times and spaces of other practices in everyday life.

\section{Desynchronisation and the Falling Apart of Rhythms}

The practices involved in training in Mixed Martial Arts do not always synchronise with, or are not always able to conquer, other practices in everyday life. They can also desynchronise and fall apart. Johnny's desistance from training provides an excellent example of this kind of disruption in routine and the disassembling of the times and spaces of the practices that supported his mixed martial arts training.

Johnny had been a regular attendee at the gym for almost a year before he stopped training for about three months in the run-up to Christmas. Despite persistent encouragement from teammates and coaches asking him to come back to training, and Johnny's promised 
responses that he would 'be down next week', it was about halfway through January that Johnny returned to regular training. On his return, Johnny was asked several times by the team what had prompted his time off from training and why he had come back at this particular time. His response was usually along the lines of:

“Now Christmas is over, they've reduced my hours at ... [work] so I've got more time to train." (Johnny)

Johnny worked part-time at a retail store. Every year his employers regularly increased parttime employees' hours in the run up to Christmas to cope with demand and then cut hours at the end of the season as shoppers reduced their spending. On the face of it, Johnny's explanation of his break from training seems familiar enough. When the amount of time available to do certain practices in a day (such as working and training MMA) is limited, physical exercise routines get pushed out of the frame. Alternatively, we might say (as the quote from Southerton above describes) that engaging in one practice can rule out another. As one practice expands to consume more hours, others are given less, or in this case none at all. This is one explanation that treats time as a scarce resource to be consumed (see Shove 2009, p, 22) and which argues that practices compete for durations of time during the day/week in which to be reproduced.

However, in subsequent conversations and an interview with Johnny, he gave a more detailed explanation for his time away from training:

"Yeah... technically I had the time, but... when you're not on it... everything just kind of falls apart. If you're working a lot, it's hard to keep on top of your diet. And then you feel like you don't have the energy to go training. And then your cardio suffers, so you know you are going to have a hard time at sparring. It makes it really hard to get back to training." (Johnny)

Johnny's consideration that he "had the time" gives us reason to reflect on the argument that practices compete for time as if it is a scarce resource. The break in Johnny's training was not a result of not having enough hours in the day to practice MMA. Instead, it was that the supporting practices, including dieting and strength and conditioning, had become desynchronised. The practices required to hold this physical exercise practice in place were 
disrupted by a change in his working practices. There was objectively enough time in Johnny's day to work, train, prepare his meals, eat, go to the gym, and to rest and recover. It was the expansion of the duration and the change in the periodicity of his working hours that disassembled the times of the supporting practices, desynchronising this physical exercise practice with other practices in everyday life.

Johnny's story is a familiar one which illustrates the point that maintaining a physical exercise practice does not so straightforwardly rely on available durations of time in which to train. Instead, it depends on the healthy, eurhythmic, synchronisation of practices in everyday life. As Lefebvre writes, disruption in one practice can lead to the desynchronisation of more broadly connected practices:

"The discordance of rhythms brings previously eurhythmic organisation towards fatal disorder." (Lefebvre [1992] 2004, p, 16)

The break in Johnny's MMA practice was not a result of a change in personal commitment or a decrease in motivation; neither was it due to a shortage of time, or a change in his ability to access the gym. Instead, Johnny's break in training can be thought of as the result of a desynchronisation of a set of practices that were not well enough established or resilient to resist or adapt to a change in his working life. This example highlights the significance of the synchronisation of practices and the desynchronising effect that desistance in one practice can have on another.

\section{Recruitment Reframed as Resilience}

So how can we know which practices will become synchronised and desynchronised, which rhythms will unite in establishing routine and which will breakdown? Theories of practice offer one useful theoretical device that has been mobilised to understand how certain practitioners are caught by practices: the notion of recruitment and defection. The position asks questions about the features of a practice that enable it to capture participants. Shove and Pantzar, who introduced this concept, present this question as:

"How do practices capture the resources and energies of active practitioners on whom their survival depends?" (Shove and Pantzar 2007, p, 155) 
The question, framed in this way, underlies the idea that practices, like MMA, recruit from particular populations rather than others and sets up an analysis of the fit between the requirements of a given practice and the features of a population that might be conducive to effective recruitment. In this case, we might say between a practice and a practitioner's required and available durations of 'free time' or their 'time-profiles'. However, if we follow the argument above, that neither practitioners nor practices have fixed temporal features or requirements and that these are shaped through their enactment, we need a further way of understanding the ongoing process of how practices shape the 'time-profiles' of practitioners from which they recruit. Extending these ideas by way of a rhythmanalysis can help us to understand how practices become synchronised and desynchronised through developing resilience through repetition.

While the members of the gym at which I trained and studied were predominantly young males and often students, the most regular members (and usually, therefore, more advanced practitioners) were not a homogenous group in terms of occupation, gender or to some extent, age. Indeed those members that most regularly attended classes and exercised outside the gym worked some of the longest hours. Students, who were often accused by non-students of having 'too much free time', were some of the most irregular practitioners. One way of explaining this anomaly is that more fixed routines, at least in the first instance, provide a fertile ground for the repetition of another practice or set of practices. For example, regular working hours could well provide a structure for regular participation in evening classes. The repetition of a set of practices, once established as a strong and healthy eurhythmia, means that they are less likely to become desynchronised by changes in the first 'sponsor' practice. For example, despite various changes to his working hours, Daniel had been the longest standing member of the gym, having trained in Mixed Martial Arts for over five years:

"I used to come straight after work for the boxing class on a Thursday... I didn't have much else on and thought it would be a laugh... When I went on earlies [early work shifts] that didn't bother me..." (Daniel)

Daniel's experience provides an interesting example of adaptation to and resilience of the rhythms of training in MMA. At first, his routine was dependent on his working practices - 
the boxing class was convenient because he could attend it straight after work. However, as he trained more, he began taking more classes and developing practices of dieting and strength and conditioning. In this way, the practices involved in training in MMA developed a strong eurhythmia of their own. When his working hours changed, now making it less convenient to attend classes, Daniel described that this did not desynchronise his MMA practice. He says that this change "didn't bother" him. They did not affect his ability to attend classes and participate in training because this set of practices had become resilient, strengthened through repetition.

This argument complicates the question of recruitment framed as 'who gets captured by a practice?'. Practices do not recruit from populations indiscriminately. Practitioner's 'timeprofiles' change and so do the temporal features and requirements of practices. This complicates the notion that maintaining physical exercise routines is straightforwardly about access to available or 'free time'. The implication is that any interventions targeted at exploiting the 'free time' or the 'time profile' of practitioners needs to take account of the ways in which practices are repeated, synchronised, and desynchronised, that is in the context of the rhythms of everyday life.

"Intervention through rhythm (which already takes place, though only empirically, for example, in sporting and military training) has a goal, an objective: to strengthen or re-establish eurhythmia." (Lefebvre [1992] 2004, p, 68)

Strengthening eurhythmia, facilitating the synchronisation of practices so that they are more resilient and able to adapt to changes and desynchronisations that may occur in broader practices of everyday life, is one way that those seeking to promote and increase levels of physical activity could shape the development and maintenance of physical exercise practices. Framed in this way, the question is no longer one of which motivations and affordances enable and constrain an individual's recruitment to desirable practices, but instead one of how desirable practices can be strengthened, made more resilient to desynchronisation, and fostered to disassemble the times and spaces of less desirable practices.

\section{Conclusion}


So described, strengthening eurhythmia is about attending to maintaining synchronised combinations of healthy activities and strengthening them against disruptions. It does not necessarily equate to a return to more collectively organised temporalities. Several studies have shown that there has been a decline in collectively organised temporalities and that contemporary social life is now characterised by an individualisation of and increased flexibility in daily schedules (see, for example, Southerton, 2009). Some might refer to such accounts to explain the growing popularity of physical exercise practices like running, swimming, and cycling that can be done without the co-participation of others and the decline of collective sports like rugby and cricket as the outcomes of increasing difficulties in coordination that result from the individualising of schedules. Such an analysis would, however, miss the point that even when exercise practices like running are performed 'individually', those performances are organised within the social and temporal rhythms of everyday life - consider peak times in the gym after work when one cannot find a treadmill to run on. It is not that practices like running and swimming, by virtue of being able to be performed alone, are able to be slotted in at will around other fixed times, such as work. It is rather as I have described above, that practices say of running, working, family and social life are deeply interconnected and affect each other as part of an ongoing and changing temporal environment. It may be that certain practices currently enjoy a strong eurhythmia as they are repeated in particular sequences and combinations, but this is a result of their interrelations and interconnections, not a result of coordination based on objective temporal features or fixed requirements for individual or co-participation.

Public health would, therefore, do well to attend to how exercise is scheduled in relation to these broader and emerging temporal arrangements and to facilitate the integration of healthy combinations of activities into everyday life. Instead of more straightforwardly seeking to enrol individuals into healthier practices through providing them with more information about the benefits of exercise, or by providing increased access to facilities and environments in which to exercise, public health could attend to the creation and maintenance of healthy sets of practices, healthy rhythms. This could be done by paying more attention to changes in societal rhythms, recognising destabilising rhythms such as Friday night binge drinking, and by supporting the emergence or development of other, potentially conflicting rhythms such as early morning Saturday running clubs and events. 
(Such accounts could be developed to explain, for example, the emerging popularity of the Park Run movement in the UK. ${ }^{7}$ ) New opportunities for shaping rates of physical activity become available when the focus is shifted from influencing individuals to make healthy choices and from shaping 'social determinants' to affect recruitment and turned towards fostering healthy combinations of activities and disassembling the times and spaces of unhealthy practices. In this paper, I hope to have provided some first steps towards developing the concepts and methods required to understand and capture how reconfigurations in everyday life matter for the emergence, maintenance, and decline of physical exercise practices.

I have expanded in this paper on the example case of MMA, but attach no particular significance to this practice. Conceptualising the synchronisation of the practices involved in training in MMA with broader practices in everyday life is developed here as an example that might equally be examined in other exercise, eating, and everyday practices. Further research could, of course, explore the particularities of synchronisation and eurhythmia in such practices, but this would be in contention with the central thesis developed here. I have argued that practices do not have objective (temporal) features that shape the ways in which they connect to other practices and show that those elements are shaped by the ways that a given practice is reproduced in relation to others. Further investigation would be better suited to considering the range of ways that practices interconnect in everyday life beyond the forms of synchronisation and desynchronisation that I have described here.

\section{References}

Baum, F., 2008 The commission on the social determinants of health: reinventing health promotion for the twenty-first century? Critical Public Health 18 (4), 457-466.

doi:10.1080/09581590802443612

Beaglehole R., Bonita R., Horton R., et al. 2011. Priority actions for the non-communicable disease crisis. The Lancet 377 (9775), 1438-1447. doi:10.1016/S0140-6736(11)60393-0

\footnotetext{
7 See http://www.parkrun.org.uk/
} 
Blue, S., Shove, E., Carmona, C., and Kelly, M., P., 2016. Theories of practice and public health: understanding (un)healthy practices. Critical Public Health 26 (1), 36-50.

doi:10.1080/09581596.2014.980396

Bourdieu, P., 1977. Outline of a Theory of Practice. Translated by Richard Nice. Cambridge University Press, Cambridge.

Brown K,., 2016. The haptic pleasures of ground-feel: The role of textured terrain in motivating regular exercise. Health \& Place. doi:10.1016/j.healthplace.2016.08.012i

Cohn, S. 2014. From health behaviours to health practices: an introduction. Sociology of Health \& IIIness 36 (2), 157-162. doi:10.1111/1467-9566.12140.

Crossley, N., 2006. In the gym: motives, meaning and moral careers. Body and Society 12 (3), 23-50. doi:10.1177/1357034X06067154

Department of Health. 2011a. Start active, stay active: a report on physical activity for health from the four home countries. Last accessed: 27.10.16. Available from:

https://www.gov.uk/government/publications/start-active-stay-active-a-report-on-physicalactivity-from-the-four-home-countries-chief-medical-officers

Department of Health. 2011b. UK physical activity guidelines. Last accessed: 27.10.16.

Available from: https://www.gov.uk/government/publications/uk-physical-activityguidelines

Downey, G., 2005. Learning Capoeira: Lessons in Cunning from an Afro-Brazilian Art. Oxford University Press, Oxford.

Edensor, T., 2010. Geographies of Rhythm: Nature, Place, Mobilities and Bodies. Ashgate Publishing, Ltd..

Frohlich, K., L., Corin, E., and Potvin, L., 2001. A theoretical proposal for the relationship between context and disease. Sociology of Health \& IIIness 23 (6), 776-797.

doi:10.1111/1467-9566.00275 
Giddens, A., 1984. The Constitution of Society: Outline of the Theory of Structuration. Berkley: University of California Press.

Hand, M., Shove, E., and Southerton, D., 2005. Explaining showering: a discussion of the material, conventional, and temporal dimensions of practice. Sociological Research Online $10(2)$.

Hitchings, R., 2012. People can talk about their practices. Area 44 (1), 61-67. doi:10.1111/j.1475-4762.2011.01060.x.

Hitchings, R., and Latham, A., 2016. Indoor versus outdoor running: understanding how recreational exercise comes to inhabit environments through practitioner talk. Transactions of the Institute of British Geographers 41 (4), 503-514. doi:10.1111/tran.12138

Lee, I., Min, E., Shiroma, J. er al., 2012. Effect of physical inactivity on major noncommunicable diseases worldwide: an analysis of burden of disease and life expectancy. The Lancet 380 (9838), 219-229. doi: 10.1016/S0140-6736(12)61031-9

Lefebvre, H., [1992] 2004. Rhythmanalysis: Space, Time and Everyday Life. Translated by Stuart Elden and Gerald Moore. Edited by Stuart Elden. Continuum, London, New York.

Malhotra, A., Noakes, T., and Phinney, S., 2015. It is time to bust the myth of physical inactivity and obesity: you cannot outrun a bad diet. British Journal of Sports Medicine, 49 (15), 967-968. doi: 10.1136/bjsports-2015-094911

Maller, C., 2015. Understanding health through social practices: performance and materiality in everyday life. Sociology of Health \& Illness 37 (1), 52-66. doi: 10.1111/14679566.12178

Marmot, M., et al., 2010. Fair society, healthy lives: the marmot review: strategic review of health inequalities in england post-2010. Last accessed: 27.10.16. Available from:

http://www.instituteofhealthequity.org/projects/fair-society-healthy-lives-the-marmotreview 
Nettleton, S., and Green, J., 2014. Thinking about changing mobility practices: how a social practice approach can help. Sociology of Health \& Illness 36 (2), 239-251. doi: 10.1111/14679566.12101

NICE Pathways. 2016. Physical activity overview. Last accessed: 21.10.16. Available from: http://pathways.nice.org.uk/pathways/physical-activity

NHS Choices. 2015. Physical activity guidelines for adults. Last accessed: 27.10.16. Available from http://www.nhs.uk/Livewell/fitness/Pages/physical-activity-guidelines-for-adults.aspx.

Prince, S., Adamo, K., Hamel, M., et al., 2008. A comparison of direct versus self-report measures for assessing physical activity in adults: a systematic review. International Journal of Behavioral Nutrition and Physical Activity, 5 (1), 1.

Reckwitz, A., 2002. Toward a theory of social practices: a development in culturalist theorizing. European Journal of Social Theory, 5 (2), 243-263.

doi:10.1177/13684310222225432

Sanchez, R., and Spencer, D., 2013. Fighting Scholars: Carnal Ethnographies of Martial Arts and Combat Sports. Anthem Press, London.

Schatzki, T., Knorr-Cetina, K., and von Savigny, E., 2001. The Practice Turn in Contemporary Theory. Routledge, London.

Shove, E., and Spurling, N., 2013. Sustainable Practices: Social Theory and Climate Change. Routledge.

Shove, E., 2009. Everyday practice and the production and consumption of time. In Time, Consumption and Everyday Life: Practice, Materiality and Culture. Edited by Shove E., Trentmann, F., and Wilk, R. Berg, Oxford.

Shove, E., and Pantzar, M., 2007. Recruitment and reproduction: the careers and carriers of digital photography and floorball. Human Affairs, 17 (2), 154-167. doi: 10.2478/v10023-0070014-9. 
Shove, E., Pantzar, M., and Watson, M., 2012 The Dynamics of Social Practice: Everyday Life and How it Changes. Sage, London.

Shove, E., Watson, M., and Spurling, N., 2015. Conceptualizing connections: energy demand, infrastructures and social practices. European Journal of Social Theory, 18 (3), 274-287. doi: $10.1177 / 1368431015579964$

Smith, R., and Hetherington, K., 2013. Urban rhythms: mobilities, space and interaction in the contemporary city. The Sociological Review, 61 (1), 4-16. doi:10.1111/1467-954X.12050

Southerton, D., 2006. Analysing the temporal organization of daily life: social constraints, practices and their allocation. Sociology, 40 (3) 435-454. doi: 10.1177/0038038506063668

Southerton, D., 2009. Re-ordering temporal rhythms: coordinating daily practices in the uk in 1937 and 2000. In Time, Consumption and Everyday Life: Practice, Materiality and Culture. Edited by Shove E., Trentmann, F., and Wilk, R. Berg, Oxford.

Spencer, D., 2012. Ultimate Fighting and Embodiment: Violence, Gender and Mixed Martial Arts. Routledge.

Thompson, L., and Kumar, A., 2011. Responses to health promotion campaigns: resistance, denial and othering. Critical Public Health, 21 (1), 105-117.

doi:10.1080/09581591003797129

Wacquant, L., 2004. Body and Soul: Notebooks of an Apprentice Boxer. Oxford University Press, Oxford.

Wacquant, L., 2014. Homines in extremis: what fighting scholars teach us about habitus. Body \& Society, 20 (2), 3-17. doi: 10.1177/1357034x13501348

Wacquant, L., 2015. For a sociology of flesh and blood. Qualitative Sociology, 38: 1-11. doi:10.1007/s11133-014-9291-y

Ward, M., 2016. Swimming in a contained space: Understanding the experience of indoor lap swimmers. Health \& Place. Doi: 10.1016/j.healthplace.2016.09.006 
Warde, A., 2005. Consumption and theories of practice. Journal of Consumer Culture, 5 (2), 131-153. doi: $10.1177 / 1469540505053090$

Warde, A., 2013. What sort of a practice is eating. In Sustainable Practices: Social Theory and Climate Change, edited by Shove, E., and Spurling, N. Routledge. 


\section{Essential Title Page Information}

Title

Maintaining Physical Exercise as a Matter of Synchronising Practices: Experiences and Observations from Training in Mixed Martial Arts

\section{Author name and affiliation}

Stanley Blue ${ }^{a}$

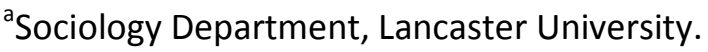

D06, FASS Building, Lancaster University, Bailrigg, Lancaster, LA1 4YD

s.blue@lancaster.ac.uk

\section{Corresponding author}

Stanley Blue, s.blue@lancaster.ac.uk 